\title{
ATUAÇÃO DO PEDAGOGO E AS QUESTÕES DE GÊNERO E IDENTIDADE NA EDUCAÇÃO INFANTIL
}

\author{
RENDIMIENTO DE PEDAGOGE Y PROBLEMAS DE GÉNERO E IDENTIDAD \\ EN LA EDUCACION INFANTIL EARLY
}

\author{
PEDAGOGUE ACTION AND GENDER AND IDENTITY ISSUES IN CHILDREN \\ EDUCATION
}

Solange Aparecida de Souza MONTEIRO ${ }^{1}$
Paulo Rennes Marçal RIBEIRO

RESUMO: As principais reflexões apresentadas no artigo dizem respeito às questões gênero e identidade na educação infantil na perspectiva educação escolar e a experiência do profissional pedagogo na forma como é produzida a sua subjetividade. Nesse sentido, o desenvolvimento dos papéis de gênero e a construção da identidade são socialmente elaborados e aprendidos desde o nascimento, com base em relações sociais e culturais que se estabelecem a partir dos primeiros meses de vida, mas é no princípio da educação que a criança começa a perceber a diferença entre o feminino e o masculino. Em consequência, o artigo prioriza diversas questões temáticas, processo, portanto, plural, polêmico e complexo, no qual práticas educacionais e pedagógicas cotidianas incitam questões e problemas teóricos, ao mesmo tempo, que novas teorias e movimentos sociais provocam ou transformam essas práticas pedagógicas. $\mathrm{O}$ artigo traz um estudo dessa temática e é constituído a partir de diferentes posições disciplinares, teóricas e alguns conceitos da questão de gênero e identidade. É importante enfatizar que a compreensão desses conceitos possibilita identificar os valores atribuídos a homens e mulheres bem como as regras de comportamentos decorrentes desses valores. Com isso, fica evidente: a influência desses valores e regras no funcionamento das instituições sociais, como a escola; a influência de uma possibilidade que permita pensar nas diferenças sem transformá-las em desigualdades, ou seja, sem que as diferenças sejam pontos de partida para discriminação.

PALAVRAS-CHAVE: Pedagogo. Genero. Identidade. Educação infantil.

RESUMEN: Las principales reflexiones presentadas en el artículo se refieren a las cuestiones de género e identidad en la educación de la primera infancia en la perspectiva de la educación escolar y la experiencia del pedagogo profesional en la forma en que se produce su subjetividad. En este sentido, el desarrollo de los roles de género y la construcción de la identidad se elaboran y aprenden socialmente desde el nacimiento, basados en las relaciones sociales y culturales que se establecen desde los primeros

${ }^{1}$ Instituto Federal de Educação Ciência e Tecnologia de São Paulo (IFSP), Araraquara - SP - Brasil. Doutoranda em Educação Escolar. Mestra em Processos de Ensino, Aprendizagem e Inovação. ORCID: <http://orcid.org/0000-0002-1640-0266>.E-mail: solmonteiro@ifsp.edu.br

${ }^{2}$ Universidade Estadual Paulista (UNESP), Araraquara - SP - Brasil. Docente do Programa de PósGraduação em Educação Sexual, e no PPG Educação Escolar. ORCID: <http://orcid.org/0000-0002-15525702>.E-mail: paulo.rennes@unesp.br 
meses de vida, pero es en el comienzo de Educación que el niño comienza a percibir la diferencia entre lo femenino y lo masculino. En consecuencia, el artículo prioriza varias cuestiones temáticas, por lo tanto, plurales, controvertidas y complejas, en las que las prácticas educativas y pedagógicas cotidianas incitan a cuestiones y problemas teóricos, al mismo tiempo, que las nuevas teorías y movimientos Provocar o transformar estas prácticas pedagógicas. El artículo presenta un estudio de este tema y, están constituidos a partir de diferentes posiciones disciplinarias, teóricas y algunos conceptos de la cuestión del género y la identidad. Es importante destacar que la comprensión de estos conceptos permite identificar los valores atribuidos a hombres y mujeres, así como las reglas de comportamientos derivados de estos valores. Por lo tanto, es evidente: la influencia de estos valores y reglas en el funcionamiento de las instituciones sociales, como la escuela; La influencia de una posibilidad que permite pensar en las diferencias sin transformarlas en desigualdades, es decir, sin que las diferencias sean puntos de partida para la discriminación.

PALABRAS CLAVE: Educador. Genero. Identidad. Educación en la primera infancia.

ABSTRACT: The main reflections presented in the article relate to gender and identity issues in children's education in the school education perspective and the experience of the pedagogical professional in the way their subjectivity is produced. In this sense, the development of gender roles and the construction of identity are socially elaborated and learned from birth, based on social and cultural relations established from the first months of life, but it is at the beginning of education that the child begins to perceive the difference between the feminine and the masculine. Consequently, the article prioritizes a number of thematic issues, a process that is therefore plural, polemical and complex, in which daily educational and pedagogical practices incite theoretical questions and problems, at the same time, that new theories and social movements provoke or transform these pedagogical practices. The article brings a study of this subject and is constituted from different disciplinary positions, theoretical and some concepts of the question of gender and identity. It is important to emphasize that understanding these concepts makes it possible to identify the values attributed to men and women as well as the rules of behavior resulting from these values. With this, it is evident: the influence of these values and rules on the functioning of social institutions, such as school; the influence of a possibility that allows us to think about differences without turning them into inequalities, that is, without differences being starting points for discrimination.

KEYWORDS: Pedagogue. Gender. Identity. Children education.

\section{Introdução}

Pensar sobre as formas de como o pedagogo e as questões de gênero e identidade na Educação Infantil nos remete a compreender a "verdade sobre o sexo e a sexualidade" (FOUCAULT, 1988), e como ela é veiculada pelo dispositivo da educação institucional, bem como, a busca por enxergá-la através de uma lente que a entende como um grande desafio contemporâneo verificando como estas "verdades" têm "negociado e constituído" 
e como os processos de subjetivação de grupos identitários são estigmatizados nas práticas educativas. Assim, tem-se como intento olhar para a experiência do profissional pedagogo na forma como é produzida a sua subjetividade e a forma como os sujeitos fazem a experiência de si a partir dos jogos de poder e verdade, os quais caracterizam as condições de produção discursivas históricas, sociais e culturais de dada época e em determinado espaço.

Os autores Paniagua e Palácios (2007), afirmam que a expressão educação infantil surge logo depois a promulgação da lei de reforma educativa espanhola de 1990, referindo-se ao atendimento em escolas de meninos e meninas de alguns meses de vida até os 6 anos. Existiram tentativas de abandonar o status educativo dessa faixa etária, mas esta ideia do trabalho com crianças pequenas caracterizada pela educação infantil atrelouse tanto aos profissionais como aos pais.

Os estudos foucaultianos $(1979 ; 2007)$, defendem que o sujeito se constitui por meio de práticas discursivas. Estas se fazem por meio de processos de subjetivação, que é o resultado de uma construção que se dá no interior de um espaço demarcado por três eixos: Ser-Saber; Ser-Poder; Ser-Ética.

A Educação infantil em seu contexto histórico fundamenta-se na forma de entender e compreender a sua contemporaneidade. O modo de pensar, compreender e educar a criança sofreu alterações de acordo com as modificações da concepção da sociedade em que estava inserida. A criança, entendida como um ser diferente do adulto, por apresentar diferenças quanto à idade, maturidade e comportamentos típicos adquiria limites específicos associados à cultura, ao momento histórico e aos papeis já estabelecidos pela própria sociedade.

Superar a Educação Sexual fundamentada nas estruturas biológicas centradas na noção de que sexualidade e sexo (órgão genital e relação sexual) são a mesma coisa. Deve-se avançar no sentido de ter outras categorias, critérios, conceitos para tratarmos a sexualidade como parte essencial da vida, e se descortinar as riquezas de experiências da sexualidade e das subjetividades no âmbito institucional, social, histórico, entre outros. Nesse sentido, buscar olhar para a sexualidade humana na educação infantil de forma mais crítica, emancipatória e libertária. Para tanto, devemos desconstruir o discurso e a prática dos modelos conservadores de educação sexual, cujos formatos reafirmam o patriarcalismo, o machismo, a submissão feminina, a segregação da diversidade e a opressão dos sexos. 
Mas o que entendemos por sexualidade? Uma vez que é muito comum apenas reproduzirmos conceitos produzidos pela família, pelo senso comum, e no lar, pela família sem nenhuma reflexão a respeito, ou até mesmo sem nenhuma criticidade ou pergunta a nós mesmos: o que é sexualidade para mim mesmo? Como vejo minha sexualidade: pelo olhar do outro, ou pelo meu olhar, ou pelo olhar da ciência, ou pelo olhar da mídia, entre outros?

Numa educação que visa à autonomia é necessário, que a escola proporcione para a criança um ambiente socio-moral cooperativo com relações de afetividade, justiça e de respeito mútuo. Assim, a aprendizagem acontecerá em um vínculo de um processo entre subjetividades e afetividades, pois aprender implica em desejo que deve ser reconhecido pelo aluno. O elemento humano é fundamental em uma relação pedagógica para a comunicação em nível de ensino/aprendizagem. Quando a criança percebe o afeto existente, começa a adquirir segurança no fazer ou deixar de fazer algo, tornando mais independente e autônoma quanto suas decisões. O sucesso ou fracasso escolar, junto com a dificuldade de aprendizagem seriam entendidos por ela e se poderia trabalhá-las de forma mais sistemática e consciente sem o sentimento de culpa, incompetência ou rejeição, logo que entenderiam que essas situações como naturais passíveis de serem resolvidas com o apoio de um adulto que o ame e se preocupa com ela. $\mathrm{O}$ aprender voltado a um pensar mais dinâmico e mais flexível pronto para o desconhecido, deve-se colocar como prioridade a qualidade afetiva entre os envolvidos, que inclui o exercício da autoestima, da autoconfiança, da autonomia e da amorosidade em geral, assim, a criança, na educação infantil, poderá desenvolver-se como um ser seguro e confiante. Essa relação afetiva no processo ensino/aprendizagem exigirá do professor uma atitude de respeito e amor interior para conviver com a própria simplicidade e autenticidade de uma emoção pessoal. A inclusão do afeto na sua pratica pedagógica poderá resultar em consequências inesperadas tanto para o próprio professor quanto para a criança, de forma positiva. Logo que, o desejo mais profundo de qualquer criança é o de ser compreendida e, esse simples fato, possibilitará um processo de comunicação que facilitará a aprendizagem.

Nesse sentido, a última fase foucaultiana nos é interessante, na medida em que pode nos instigar a pensar sobre como nós entendemos, sentimos e entendemos nossa sexualidade e nossa(s) subjetividade(s) e a partir disso, como nós conduzimos nossas ações em relação à sexualidade na construção de si na relação com o outro.

Foucault (2004) em sua última fase passa, então, a investigar as "técnicas de si", o "cuidado de si" na cultura greco-romana. Por técnicas de si o estudioso compreende os 
tipos de operações que os indivíduos podem realizar por eles mesmos ou com ajuda de outros, em determinada época e sociedade, em seu próprio corpo, seus pensamentos e em suas condutas, "de modo a produzir neles uma transformação, uma modificação, e a atingir um certo estado de perfeição, de felicidade, de pureza" (FOUCAULT, 2004, p. 95).

Dessa forma podemos considerar que sexo não é apenas sinônimo de gênero, pois, sexo refere-se às características anatômicas do ser feminino e do masculino, enquanto gênero é arquitetado por diferentes culturas e elementos sociais. No ponto de vista de Braga (2010) com o aval em Louro (2001), a expressão gênero, inicialmente, foi utilizada justamente para marcar as diferenças entre homens e mulheres, nesse sentido, falar de relações de gênero significa ponderar acerca das características atribuídas a cada sexo pela sociedade e sua cultura. Nesse mesmo entendimento, Seffner (2006) conceitua identidade de gênero como identificação de homens e mulheres vinculados aos atributos culturais. Essa consideração consente-nos entender que é nas e pelas relações sociais que são construídas as definições normativas da feminilidade e masculinidade. A escola, aparentemente, também reforça a desigualdade de gênero, assim como, de identidade sexual, em muitos casos, alimentando a ideia da inferioridade feminina, ideia essa, que é proveniente de uma herança histórica que se vincula a aprendizados de diferentes culturas.

\section{A organização do trabalho pedagógico na educação infantil}

A Educação Infantil é um espaço marcado por características singulares de organização e funcionamento. $\mathrm{O}$ que se faz dentro desse espaço educativo é diferente de outras instituições e o nível de ensino requer dos profissionais que ali atuam uma postura diferente, enquanto professores e professoras de crianças. Desse modo, o trabalho pedagógico na Educação Infantil requer competências e habilidades específicas.

Todo trabalho docente precisa ser planejado e repensado para acontecer. Porém o ato de planejar e organizar a Educação Infantil não é visto como algo necessário, considerando-se que esses atos seriam a base da organização do trabalho pedagógico. Pois é através do ato de planejar que o docente irá perceber e analisar determinadas situações que podem ocorrer dentro da Educação Infantil como desafios e descobertas. Não há como trabalhar sem planejar o que se vai fazer. A organização do trabalho pedagógico é requisito fundamental para que exista seriedade e competência, e segundo Ostetto (2002, p. 17) 
A delimitação de critérios para a organização do trabalho nas creches pode ser percebida como um avanço no caminho da defesa e da efetivação dos direitos das crianças, uma vez que dá norte, sistematiza uma perspectiva minimamente comum para o território nacional, sem ser restritiva, uniforme ou prescritiva.

Assim, organizar e planejar o trabalho docente antes de tudo é a garantia do direito a criança pequena de uma educação pública infantil de qualidade, com profissionais exercendo suas funções de maneira compromissada, sem improvisos e atividades com intuito de somente passar o tempo ocioso.

Na Educação Infantil faz-se imprescindível que a organização e o planejamento sejam fundamentais. Isto, pois, favorece melhora e conforto para o desempenho das crianças. No sentido da organização vale enfatizar a necessidade também de organização do entorno do aluno para que o ambiente fique mais sadio e harmonioso. Toda a equipe escolar deve cooperar na questão da organização e do planejamento, não somente o professor, pois assim as necessidades, qualidades e especificidades individuais são mais bem respeitadas em sala de aula. Para exercer eficazmente seu trabalho todo docente de Educação Infantil precisa, de maneira organizada e sistemática, combinar meios que direcionam a prática pedagógica. Franchi (1995, p. 56) defende que “[...] a eficácia do trabalho do professor depende, previamente, de um conjunto combinado e estruturado de atitudes, princípios e pressupostos educacionais que norteiem a prática educativa.

Ou seja, para um trabalho escolar com qualidade, não há como o mesmo acontecer sem o ato de organizar e planejar. Partindo da organização do trabalho docente, perpassando pela sua efetivação enquanto prática realizada pelo professor com as crianças e chegando à finalização do trabalho, é possível reconhecer a necessidade de ressaltar a importância do registro de tudo o que se faz e acontece na sala de aula, enquanto atividades e cuidados, no período em que a criança se encontra no Centro de Educação Infantil. Assim, conforme registra Ostetto (2010, p. 8), “A proposta de registrar a experiência vivida, descrevendo e analisando a complexa trama do cotidiano educativo, tem sido apontada e assumida como essencial para a qualificação da prática pedagógica".

Nesse contexto, é inegável que o registro do trabalho traz a garantia de um mecanismo para se analisar e repensar a prática educativa, na garantia da superação dos erros levando a ascensão da qualidade do trabalho na Educação Infantil. A necessidade de se registrar deriva da riqueza de situações presentes no trabalho com a criança pequena. A instituição de Educação Infantil é um universo rico para ser analisado tanto nos 
diferentes trabalhos exercidos por diversos profissionais como pelas crianças que lá estão. Então, o ato de registrar torna-se atividade essencial e indispensável para a prática educativa.

Contudo, estes dois atos necessitam ser diários. Pois o trabalho com criança acontece durante um longo período da semana, dos meses e muitas vezes anos, não se restringindo apenas a um curto período de horas diárias. Logo, ainda conforme explicita Ostetto (2010, p. 13), “O registro diário, compreendido espaço privilegiado da reflexão do professor, converte-se em atividade vital [...] é verdadeiramente um instrumento do seu trabalho, articulando-se ao planejamento e à avaliação".

Deste modo, o registro serve de base para planejar e avaliar. Planejar as ações enquanto professor de crianças pequenas, avaliarem o trabalho realizado e o progresso da criança.

O registro destaca o vivenciado no cotidiano, é de caráter descritivo das situações, mas sua função é analítica, não se restringe apenas a descrever o que aconteceu. O registro proporciona a relação de dar continuidade nas ações pedagógicas e principalmente analisar o trabalho do professor. Pois, voltar e analisar o que está escrito são exercícios de autoconhecimento, autoanálise e autorreflexão. Neste sentido cabe explicar que a prática pedagógica do registro enquanto instrumento metodológico do professor é a

[...] base para refletir sobre o passado, para avaliar as ações do professor, para rever o cotidiano educativo e o trabalho desenvolvido com o grupo de crianças; também para reafirmar o presente e projetar o futuro (OSTETTO 2010, p. 21).

Ou seja, o ato de registrar a prática docente vem de encontro com as necessidades avaliativas, onde o professor avaliará tudo o que resultou positivamente no passado para se utilizar no presente e assim planejar o futuro. Em suma, o registro serve para o professor como um instrumento norteador que ao escrever sobre sua prática evidenciamse o fazer e o como se está fazendo- deixando nítido o trabalho realizado.

Ao escrevermos nossa experiência, nosso fazer ganha visibilidade, torna-se documento ao qual podemos retornar para rever o vivido, atribuindo-lhe outros significados e projetando outros fazeres desejados ou necessários. Por meio do registro, travamos um diálogo com nossa prática (OSTETTO 2010, p. 13).

Quando escrevemos nossa experiência, relatamos nossas práticas vivenciadas e estamos também construindo de certa forma nossa identidade. Pois é a maneira com que o professor atua em sala de aula, o que ele planeja, o que necessita para transmitir 
conhecimento faz com que ele vá construindo sua identidade bem como sua história enquanto docente. Todo professor possui uma história que o identifica como professor, Oliveira (2006) aborda que pensar a construção da identidade da perspectiva da rede de significações nos afasta de um entendimento linear dos modos de relação entre as identidades e nos leva a conceber cada posição identitária articulada com outras linhas de identidade numa teia de relações e disposições sociais e históricas. Uma trajetória marcada por lutas e conquistas individuais, que contribuem para o processo de construção da identidade. Todo professor tem uma história a contar e ao ter essa oportunidade. Oliveira (2006), aponta que ao narrar sua história é um meio de cada pessoa atribuir um sentido à sua experiência, dar um significado a quem ela é e perceber como este é construído no mundo social. Isso ocorre à medida que a narrativa organiza um discurso em que se imbricam significações diversas, que formam redes e criam uma realidade social no embate com diferentes interlocutores (reais ou internalizados) para legitimar sentidos. Nesse sentido, Grillo (2004 p.78) diz: "A docência envolve o professor em sua totalidade; sua prática é resultado do saber, do fazer e principalmente do ser, significando um compromisso consigo mesmo, com o aluno, com o conhecimento e com a sociedade e sua transformação"

É no contexto escolar contemporâneo que a educação sexual se torna uma ponte que nos liga a história da sexualidade, apontando os mecanismos produtivos da norma sexual e de gênero, e desenvolver trabalhos que busquem estratégias de resistência à reprodução dessa norma e tornando o espaço educativo mais crítico, sensível e consciente. Espaço esse que favorece a intenção da educação como um ato político.

O professor ao narrar sua história traz consigo toda uma identidade, ou seja, características inerentes à sua construção individual. $\mathrm{O}$ professor não constrói sua identidade apenas com formações acadêmicas e cursos de profissionalização, sua identidade é construída através de seus registros. Registros estes de toda sua carreira docente. Registros feitos através de planos de aula, planejamento e até mesmo diários, relatando tudo o que acontece em sala de aula. A identidade de um professor é construída por seus registros diários.

Contudo, não é preciso que o mesmo se faça como algo frio e sem vida. O registro é algo pessoal do professor, deve ter a sua identidade, cada professor tem o direito de fazer seu registro como bem entender, sendo ele singular e único em seu jeito de ser. Para Ostetto (2010, p. 25) o registro é espaço específico de cada educador, é pessoal, particular, 
seu caráter é individual. Não pode ser concebido, nem utilizado, como forma de controle. A menos que o próprio educador deseje compartilhar.

Sendo assim, o registro do professor é a porta de entrada para que se possa conhecer sua prática docente, a forma de avaliar seus alunos e também de autoavaliação, construindo assim o percorrer de uma história e a identidade de um educador responsável e que busca sempre o aprimoramento de sua carreira.

\section{Cuidar e educar: requisitos necessários ao trabalho pedagógico na escola infantil}

O trabalho realizado na Educação Infantil contribui com os cuidados que a família tem com a criança e por ainda ser uma instituição escolar vem complementar essa ação, com a realização do trabalho de educar. Vivencia-se, tanto pelos profissionais que trabalham com crianças pequenas como pela própria sociedade, um período de transição de uma visão assistencialista para uma visão pedagógica do que se é feito nos centro de Educação Infantil, evidenciando que conforme aponta Oliveira (2006), que o trabalho em creche vive um período de transição entre uma concepção que o definia como de cunho assistencial para outra, que passou a acentuar a dimensão pedagógica de educação e cuidado de crianças bem pequenas.

O trabalho em um Centro de Educação Infantil transcende a concepção de que as crianças que lá estão necessitam apenas de cuidados. Visão própria deriva do processo de criação de muitas instituições de Educação Infantil, que inicialmente foram criadas para compensar as carências sociais que muitas pessoas de classes menos favorecidas possuíam e não tinham meios de proporcionar condições de cuidados básicos a seus filhos, essa concepção culminou por solidificar na sociedade uma visão assistencialista dos cmeis e principalmente da educação infantil, distorcendo ainda na atualidade o trabalho que se é realizado (BRASIL, 1998).

As instituições de Educação Infantil eram vistas como um ambiente onde se realizava apenas cuidados de higiene, trabalho este compreendido como de caráter assistencialista às crianças. Com o passar do tempo, reconheceu-se o direito da criança, principalmente as de classes menos favorecidas, de receber, não apenas cuidados com a sua higiene, mas também um trabalho voltado para aprendê-lo, para educá-lo. Essa inversão de conceitos leva-se a perceber que as "[...] instituições não são mais vistas com o um 'mal necessário', mas como uma complementação da ação da família” (CRAIDY, 1998). Mal no sentido de transferir dos pais as responsabilidades sociais que a eles são 
atribuídos, como cuidar e manter a criança em condições sadias de higiene, alimentação e promoção de um desenvolvimento favorável, mas necessário no sentido de que há situações familiares que não proporcionam a garantia desses princípios básicos.

Para Felipe (1998), o desenvolvimento sadio da criança, a instituição de Educação Infantil tem como responsabilidade o educar e cuidar, onde estas ações são representadas como um desafio para a instituição, pois a mesma é um espaço diferente do ambiente.

Educar em um Centro de Educação Infantil relaciona-se a ensinar saberes que são necessários a vida da criança e ao seu desenvolvimento e primordialmente. Craidy 1998, p. 24, aborda que propiciar situações de cuidados, brincadeiras e aprendizagens orientadas de forma integrada e que possam contribuir para o desenvolvimento das capacidades infantis de relação interpessoal, de ser e estar com os outros em uma atitude básica de aceitação, respeito e confiança, e o acesso, pelas crianças, aos conhecimentos mais amplos da realidade social e cultural.

O aprendizado e a transmissão de conhecimento são ricos aliados na Educação Infantil. A cultura de um povo, seus costumes e tradições são transmitidos pelas práticas cotidianas. O trabalho pedagógico no Centro de Educação Infantil contribui para o acesso das crianças ao conhecimento que a sociedade construiu e principalmente os valores sociais que estabeleceu. Complementando o ato de educar, está o de cuidar. Cuidar relaciona-se primeiramente à manutenção de uma higiene sadia, contemplando ações que tragam saúde à criança e bem estar físico. Cuidar é "zelar pelo bem-estar ou pela saúde" (MICHAELIS, 2019).

Os cuidados com a higiene da criança são constantes e inevitáveis, e muitas vezes exigem saberes adicionais aos pedagógicos, necessitando saberes que transcendem os conhecimentos pedagógicos e acima de tudo auxiliam a proporcionar um desenvolvimento humano sadio, valorizando e desenvolvendo das capacidades individuais (BRASIL 1998).

As relações de cuidado que o professor estabelece um vinculo afetivo com a criança,

[...] para cuidar é preciso antes de tudo estar comprometido com o outro, com sua singularidade, ser solidário com suas necessidades, confiando em suas capacidades. Disso depende a construção de um vínculo entre quem cuida e quem é cuidado [...] cuidar da criança é sobretudo dar atenção a ela como pessoa que está num contínuo crescimento e desenvolvimento, compreendendo sua singularidade, identificando e respondendo às suas necessidades (BRASIL 1998, p. 25). 
As ações de cuidado da criança são carregadas de afetos e carinhos, onde o vínculo com a criança se estabelece, sendo esse um auxiliador na realização dos cuidados á criança pequena. É cabível de se questionar que se as crianças não tivessem afinidade com quem é responsável legalmente por elas durante um determinado período do dia, a realização do trabalho seria difícil e encontraria diversas barreiras. Sendo assim, o professor infantil é uma figura importante para a adaptação da criança ao ambiente escolar, é por meio das atitudes do professor que se transmitirá segurança e confiabilidade. A criança precisa se sentir segura em meio aquela instituição que se encontra e que a acolhe. Certificar-se que naquele ambiente ela terá carinho, apoio e o mais importante- de que serão respeitadas conforme suas qualidades e necessidades. Tanto professor como a instituição, necessitam estabelecer estratégias para promover a adaptação a essas crianças. E que

[...] os diferentes profissionais envolvidos na Educação Infantil [...] têm uma importante tarefa a cumprir, na tentativa de proporcionar às crianças experiências significativas, que venham a contribuir para um desenvolvimento agradável e sadio. São, portanto, mediadores entre a criança e o meio (CRAIDY 1998, p. 9).

A Educação Infantil constitui-se um espaço privilegiado para promoção do desenvolvimento da criança e os profissionais que ali estão são privilegiados de poderem ter sob suas responsabilidades essas oportunidades. O professor infantil tem então uma enorme responsabilidade no transcorrer do seu trabalho. Por esse motivo, e pelo fato de exercer influência no processo de desenvolvimento da criança é irrelevante seu papel e, acima de tudo, o que faz enquanto prática na realização do trabalho.

\section{Saberes para a prática pedagógica: questões de gênero e experiência}

Percebe-se que o trabalho pedagógico realizado nas instituições de Educação Infantil é exercido, em sua grande maioria por mulheres. Conta-se atualmente com homens exercendo o trabalho, mas as mulheres predominam nos Centros de Educação Infantil. Neste espaço onde a feminilidade está presente em diversos aspectos, desde a organização do espaço, decoração e profissionais que trabalham na instituição, onde a realização do trabalho com a criança de certa forma trás consigo um pouco deste gênero feminino.

Cerisara (2002) discute a idéia de que a questão de gêneros implica na representação de papeis e funções docentes. Conforme a autora, o gênero influência na 
realização das atividades com a criança e a busca de uma construção de identidade profissional vai além de gêneros e papeis preestabelecidos pela sociedade. Atuar como docente trás marcas no trabalho que são próprias das mulheres e que a realização dos fazeres escolar também.

Como caracteriza Cerisara (2002, p. 30) "Insistir sobre o caráter social das relações de gênero significa considerar que, além de uma categoria biológica, o gênero também é uma categoria histórica". Histórica no sentido de que a mulher sempre foi colocada em nível inferior na sociedade, na questão da garantia de seus direitos e com as implicações do papel de ser mãe, primordialmente. A sociedade aponta uma visão da professora relacionada com a da mulher que ocupa um lugar na sociedade mais afetivo e doméstico. Porém um lugar que a mesma foi colocada e que para muitos ela não poderia desocupar, ou exercer suas funções em outro.

O caráter feminino na realização do trabalho com a criança pequeno deixa claro como as funções maternas se confundem com as funções de professora. As questões relacionadas ao gênero estão presentes nas práticas cotidianas, onde se é reproduzido o que culturalmente é função de mulher. E como a mulher historicamente, sempre ocupou um papel inferior na sociedade, essa inferioridade é transmitida na prática docente.

Reproduzir o trabalho doméstico na instituição de educação infantil é garantir que para ser professora não é preciso ter uma formação acadêmica e sim realizar reproduções do trabalho doméstico que se aprende no cotidiano e na transmissão de conhecimentos oriundos da prática diária.

Percebe-se então que o que se realiza na prática com as crianças está relacionado com o papel afetivo e cuidador que a mulher tradicionalmente exerce na sociedade. Nessa óptica convém destacar a análise realizada por Kramer em relação as atividades desempenhadas na Educação Infantil e sua associação ao trabalho doméstico da mulher, desempenhado no âmbito familiar. Seu estudo aponta que:

As atividades do magistério infantil estão associadas ao papel sexual, reprodutivo, desempenhado tradicionalmente pelas mulheres, caracterizando situações que reproduzem o cotidiano, o trabalho doméstico de cuidados e socialização infantil (KRAMER 2002, p. 125).

O trabalho pedagógico em um Centro de Educação Infantil é associado ao trabalho da mulher em casa, tendo em si um caráter reprodutivo na realização de práticas com as crianças. Esse entendimento é uma distorção da real finalidade da Educação Infantil e do que se deve realizar dentro de uma instituição para crianças de zero a cinco anos de idade. 
O trabalho doméstico da mulher não é remunerado, portanto ao se associar o trabalho doméstico com o trabalho de educar e cuidar crianças em um Centro de Educação Infantil "Considera-se que o trabalho do profissional de educação infantil necessita de pouca qualificação e tem menor valor" (KRAMER 2002, p. 21) perante a sociedade. Se a mulher não recebe vencimentos pelo seu trabalho então a professora, que segundo a visão errônea da sociedade faz igual, também não deveria receber, ou então receber uma quantia inferior a relevância do trabalho que realiza.

Ainda é presente no imaginário das pessoas que o trabalho na Educação Infantil é inferior e que pode ser exercido sem nenhum preparo. Muitas pessoas pensam que o trabalho se restringe a limpar e cuidar dos pequenos, bem como reproduzir o trabalho doméstico no Centro de Educação Infantil. Esta forma de compreender o trabalho dos profissionais de Educação Infantil,

[...] camufla as precárias condições de trabalho, esvazia o conteúdo profissional da carreira, desmobiliza os profissionais quanto às reivindicações salariais e não os leva a perceber o poder da profissão (KRAMER 2002, p.21).

Conceber a educação da criança como uma cópia da educação que uma mãe pode dar a seu filho é negar que para ser professora é preciso de um preparo, e que ser professor necessita de saberes que se aprendem muitas vezes no período de formação acadêmica, e que ser profissional requer lutas por seus direitos como trabalhador.

A precariedade com que muitos Centros de Educação Infantil precisam conviver é escondida com a falta de profissionalização. Ao se compreender que para atuar na educação infantil qualquer um pode realizar esse trabalho, a sociedade acaba não vendo necessidade em mantê-la em melhores condições. Se os profissionais que atuam nos Centros Municipais de Educação Infantil não são qualificados, não se há necessidade de valorizar o trabalho e o profissional.

Convém destacar também a forma como a autora denomina o trabalhador de Educação Infantil, denominando-o profissional. Evidencia uma preocupação em mostrar o caráter sério e sistemático do trabalho que é desenvolvido na instituição de Educação Infantil em que se exige alguém habilitado para o exercício das funções e não como se constata no imaginário popular, de que qualquer um, principalmente mulher, e que possua experiência em afazeres domésticos, pode cuidar de criança.

A questão do gênero, representadas pelas práticas culturais e sociais femininas, implica consequentemente a desvalorização do trabalho docente, de modo que "A 
educação infantil, marcada por um quadro de desigualdade [...] tem na questão de gênero mais uma variável para a desvalorização do trabalho dos profissionais que se dedicam ao atendimento das crianças de 0 a 6 anos." (KRAMER 2002, p. 126). Assim, aptidões domésticas são levadas muito mais em conta do que a formação que o individuo possui, e que isso para muitos já é suficiente. Ser professor infantil não é reproduzir cuidados domésticos, portanto

[...] ao ser enfatizado o jeito, acaba-se por aceitar pessoas com pouca ou nenhuma formação, o que leva a uma baixa remuneração e uma alta rotatividade, pois não há perspectivas em termos de carreira" (KRAMER 2002, p. 126).

A autora também discute a identidade construída por inúmeros profissionais que se deixam chamar de tias, tanto entre colegas, familiares e principalmente entre as crianças. Assim, critica esse chamamento "tia" como a "permanência de um título sem valor" e "prêmio de consolação de uma trajetória que já teve status" (KRAMER 2002, p. 126). Deixa claro que para muitos professores ser tia é um consolo, uma compensação pelo desprestígio profissional que a carreira docente vem enfrentando. Ser tia vem compensar tanto as carências afetivas das crianças e as dos professores, pois para muitas sendo tias, se realizam como profissionais.

A associação do trabalho pedagógico que se realiza em um Centro de Educação Infantil com o trabalho doméstico e suas práticas cotidianas representa a manutenção da desvalorização dos profissionais que atuam como professores de crianças.

\section{As dimensões afetivas e de gênero na educação infantil}

Trabalhar com crianças e não estabelecer vínculos afetivos com elas é difícil. Porém, é necessário sempre repensar qual é a função primordial do professor de crianças pequenas. Ao se cuidar de uma criança o afeto surge, dando riqueza e alegria tanto para o adulto como a criança. Negar o afeto é pensar a Educação Infantil não realizada por seres humanos dotados de sentimentos e marcados por uma história de vida.

Na obra A Arqueologia do Saber, Foucault (2009) aponta potencialidades da análise do discurso como ferramenta metodológica, várias pesquisas têm recorrido a esse conceito, assim o fizemos também para um percurso teórico-metodológico que nos permitisse analisar e problematizar as questões acerca da compreensão de diversidade, identidade, gênero, modos de existência e sexualidade na educação infantil. 
Foucault (2009), nos aponta que o que foi dito instaura uma realidade discursiva, e sendo o ser humano um ser discursivo, criado ele mesmo pela linguagem, a Arqueologia é o método para desvendar como o homem constrói sua existência e delas se apropriando, insiste em sua perpetuação.

Esta prática discursiva se define como um "conjunto de regras anônimas, históricas, sempre determinadas no tempo e no espaço, que definiram, em uma dada época e para uma determinada área social, econômica, geográfica ou linguística, as condições de exercício da função enunciativa" (FOUCAULT, 2009, p. 133).

Zagury (2006) evidencia que a relação entre professor e aluno é importante, porém deve-se haver um limite entre o permissível. Isto, pois, o afeto vai existir, mas que esse sentimento não deve ser confundido com um método para se trabalhar com a criança. Na Educação Infantil, esse sentimento é mais visível, porém, é preciso refletir sobre a situação que uma relação afetiva com a criança pode ter.

Não se trata de negar o afeto e o carinho, mas que o mesmo aconteça dentro de um limite, pois a função social e profissional que é competida ao professor infantil não é compensar carinhosamente uma criança por aquilo que se julga ser o certo. É preciso ter um extremo cuidado para que os adultos não desenvolvam sentimentos e atitudes de proteção, carinho e atenção especiais para uma determinada criança, deixando que as outras se sintam preteridas ou rejeitadas (FELIPE, 1998). O trabalho pedagógico e cuidador devem ser extensíveis a todas as crianças, sem distinção de nenhum aspecto.

Nas instituições de Educação Infantil está presente o chamamento dos professores e professoras de tias e tios. Esta forma de se referir aos profissionais, tanto aqueles que são responsáveis em cuidar e educar as crianças como aos demais profissionais que estão trabalhando na instituição, tais como auxiliares de limpeza, cozinheira(o), diretora(or), coordenadora(or) pedagógica(o), estagiárias (os), é justificada pela presença do afeto que está implícito no trabalho pedagógico com a criança.

Para Freire (2009), o tratamento de uma professora de "tia" não é considerado louvável, muito menos justificável. Suas considerações apontam a necessidade de se repensar esse tratamento, estabelecendo uma reflexão voltada a comparar o ato do tratar pessoal com a promoção de uma desvalorização da classe docente no país. Para o referido autor "a tentativa de reduzir a professora à condição de tia é uma "inocente" armadilha ideológica [...]" (FREIRE, 2009, p. 25). Esta armadilha ideológica faz com que professores não sejam valorizados e assim eles próprios não se valorizaram, pois se 
encontram sem direitos e sem deveres e ainda sem motivação alguma pra tal desempenho educacional, pois estão sob certa ideologia.

A professora ao se assumir como tia está velando sua identidade profissional e contribuindo para a desvalorização da categoria onde o profissional está negando sua classe social e contribuindo para a manutenção da ideologia dominante, que tenta "ameigar" a vida profissional docente, fazendo com que deixem esquecido o dever de lutarem por seus direitos (FREIRE, 2009).

Desse modo, ser docente é também engajar-se na luta por valorização e reconhecimento do ato de ensinar e da pessoa que se assume professor, portanto "não é possível também ser professora sem lutar por seus direitos para que seus deveres possam ser mais bem cumpridos" (FREIRE 2009, p. 26). Ser professor requer responsabilidades profissionais, com lutas constantes, formação e atualizações em sua carreira profissional.

O papel permissivo que a escola ofereceu ao aluno permitindo que chamasse a professora de tia promoveu a "deterioração da identidade dos docentes" comprometendo a relação entre ambos (CASTRO, 2003). A relação entre professor-aluno se estabelece em um ambiente com características próprias, em um espaço que possui a finalidade de ensinar conteúdos. Convém pensar até que ponto a permissividade permeia a relação pedagógica em sala, pois o professor deve estar desvinculado de qualquer círculo de parentesco com seus alunos. O professor deve ser reconhecido como um mediador no ensino-aprendizagem e não como uma relação de parentesco, ou seja como imagem de "tia", apesar de toda afetividade que a relação aluno-professor desenvolve com seus alunos.

Ser "tia" desqualifica e rebaixa o profissional. Deteriora a imagem docente e da docência. "A denominação tia deprecia a professora e interfere na relação profissional com o aluno e a sociedade" (CASTRO 2003, p. 51). O termo tia vem negar a sociedade o caráter profissional de ser educador. Ser tia é resumir o trabalho a uma simples relação afetiva. Logo, "a denominação tia [...] reduz a distância social entre professor e aluno e incentiva a criação de laços afetivos entre eles" (CASTRO 2003, p. 51).

Lima (2007) analisa que a construção da identidade e de gênero é vivida pelas crianças da educação infantil através das brincadeiras, das palavras, dos gestos, das atividades reconhecidas como masculina e feminina. Nesse sentido, as crianças internalizam e reproduzem as relações estabelecidas por homens e mulheres, sendo que algumas, são caracterizadas pela reprodução de estereótipos socialmente atribuídos aos gêneros. Mesmo que a criança já tenha construído o núcleo de sua identidade de gênero 
até os três anos de idade, a construção da identidade de gênero é um processo que se desenvolve por toda vida. (p.46-47).

A afetividade está presente no transcorrer do trabalho realizado na Educação Infantil, é intrínseca a relação afetiva que o professor estabelece com a criança. Sendo assim, o trabalho realizado desprende do professor certa afetividade, mas essa afetividade precisa ser dosada, onde ela não ultrapasse limites aceitáveis e esconda o valor profissional da função atrás apenas do carinho desprendido e recebido pelo educador.

Os laços afetivos não podem ser colocados à frente da realização do trabalho pedagógico, como justificativa de determinadas práticas. Convém pensar a afetividade como consequência da realização do trabalho e não como um pretexto para se dar mais carinho a criança que, supostamente julga-se que não tem. Ao professor infantil, compete a realização de suas tarefas, e não compensar a criança com o carinho que se acha que a mesma não recebe. Professora, em primeiro lugar ensina, e no caso da Educação Infantil, cuida e educa. Essa relação é a que deve legitimar a figura docente e seu trabalho.

\section{Considerações finais}

Como pudemos compreender, a temática das questões de gênero na educação infantil são limitantes por implicarem mitificações do trabalho docente. A relação de cuidado que se estabelece nos primeiros anos de vida dentro do seio escolar deve e deverá existir para que humanizem as relações interpessoais. Todavia, como verificamos, recai sobre o âmbito feminino a obrigação e a necessidade de atribuição de características e tarefas específicas à docentes mulheres. Isto, pois, o binômio cuidar-educar ainda é socialmente atrelado à tarefas cotidianoas realizadas prioritariamente por mulheres.

Pensar a ideia de uma educação sexual escolar e de gênero visa incluirmos as atribuições sociais que são refletidas na escola e examiná-las de forma que possamos refletir acerca de ideologias culturais, buscando amenizar o silêncio, repressão e preconceito evidenciados. É preciso traçar reflexões acerca dos processos educativos de forma a questionar as atribuições quanto ao gênero e à sexualidade, refletidas no contexto escolar, em especial nas brincadeiras. Esperamos, por fim, que o presente estudo possibilite aos/às profissionais da educação um debate e uma discussão ajustada em reflexões críticas acerca dos temas gênero e sexualidade, que se manifestam nas experiências familiares, no contexto escolar e, sobretudo, na Educação Infantil. 
Nesse sentido, compreende-se que todas as relações próprias ao cuidado de crianças em fase escolar inicial torna-se obrigação do papel feminino. É fato que essa reflexão surge de um espelhamento da sociedade que reproduz em diferentes cotidanos a mesma atribuição: mães lavam a louça e cuidam das roupas, quem limpam as casas são as empregadas domésticas, quem cuida das crianças na ausência dos pais são as babás. Ou seja, a fusão entre a maternidade e a função professoral não é novidade no que diz respeito à associação das funções de cuidado e da limpeza ao universo feminino em nossa sociedade.

O que nós defendemos, assim como Bazílio e Kramer (2003), é uma educação que seja capaz de humanizar as nossas crianças, uma educação solidária, com práticas coletivas de trocas de experiências e apropriação verdadeira da cidadania.

Sendo assim, não podemos compactuar com atitudes que menosprezem a carreria docente como um todo em função do gênero, ou seja, vale então dizer que há uma grande necessidade de superar o paradigma do feminino dentro do universo da educação infantil. Tornando-a uma disciplina técnica de poder que implica uma vigilância perpétua e constante dos individuos. Não basta olhá-los às vezes ou ver se o o que fizeram é conforme a regra. É preciso vigia-los durante todo o tempo da atividade e submetê-los a uma perpetua piramide de olhares (FOUCAULT, p.106). A superação vem no sentido de não atribuir à figura feminina o cuidado da maternidade, tanto pois essa atitude se faz leviana ao pensar que nem toda mulher tem vocação para ser mãe. A superação também viria para que não se contribua de forma a acentuar expressões machistas que alienam os homens de afazeres comuns e cotidianos. No caso da educação trata-se, especificamente, das práticas de higiene e cuidados pessoais para com os alunos bebês ou muito pequenos.

Em suma, a educação deve estar preparada não somente para remodelar as questões do gênero no que diz respeito ao trabalho professoral, mas também no espelhamento para as futuras gerações, os alunos, contribuindo para a fusão das dinâmicas do masculino e feminino, priorizando que o último não seja estigmatizado e que se faz necessária a inserção da temática: gênero e sexualidade no âmbito escolar, e na formação de professores e professoras, para que estes e estas possam discutir as temáticas com seus alunos e alunas sem receios e preconceitos.

\section{REFERÊNCIAS}

BAZÍLIO, Luiz Cavalieri; KRAMER, Sonia. Infância, educação e direitos humanos. São Paulo: Cortez, 2003. 
BRASIL. Referencial curricular nacional para a educação infantil / Ministério da Educação e do Desporto, Secretaria de Educação Fundamental. Brasília: MEC/SEF, 1998.

CASTRO, Gilda. Professor submisso, aluno-cliente. Reflexões sobre a docência no Brasil. Rio de Janeiro: DP\&A, 2003.

CERISARA, Ana Beatriz. Professoras de educação infantil: entre o feminino e o profissional. São Paulo: Cortez, 2002.

CRAIDY, Carmen Maria. (org.) O educador de todos os dias: convivendo com crianças de 0 a 6 anos. Porto Alegre: Mediação, 1998.

FELIPE, Jane. Aspectos gerais do desenvolvimento infantil. In: CRAIDY, Carmem Maria (org.) O educador de todos os dias: convivendo com crianças de 0 a 6 anos. Porto Alegre: Mediação, 1998

FRANCHI, Eglê Pontes (org). A causa dos professores. Campinas: Papirus, 1995.

FREIRE, Paulo. Professora sim, tia não: cartas a quem ousa ensinar. São Paulo: Olho d' água, 2009.

FOUCAULT, Michel. Microfísica do Poder. Organização e tradução de Roberto Machado. Rio de Janeiro: Edições Graal, 1979.

FOUCAULT, Michel. A Arqueologia do Saber. Rio de Janeiro: Forense Universitária, 2009.

FOUCAULT, Michel. História da sexualidade Vol.1: a vontade de saber. Tradução de Guilhon de Albuquerque e Maria Thereza da Costa Albuquerque. Rio de Janeiro,RJ: Graal, 2010.

FOUCAULT, Michel. A Ordem do Discurso, aula inaugural no Collège de France, pronunciada em 2 de dezembro de 1970. São Paulo: Edições Loyola, 2016.

KRAMER, Sônia. Formação de profissionais de educação infantil: questões e tensões. In: MACHADO, Maria Lucia de A.(org.). Encontros e desencontros em educação infantil. São Paulo: Cortez, 2002.

MAIA, Christiane Martinatti; SCHEIBEL, Maria Fani. Didática. Curitiba: IESDE Brasil, 2010.

MARCELO, Carlos. A identidade docente: constantes e desafios. Disponível em: http://formacaodocente.autenticaeditora.com.br/artigo/exibir/1/3/8 - acesso em 08/06/2011 - 20:25hs.

MEDEIROS, João Bosco. Redação científica: a prática de fichamentos, resumos, resenhas. 7. ed. São Paulo: Atlas, 2006. 
OLIVEIRA, Zilma de Moraes Ramos de. (org.) Construção da identidade docente: relatos de educadores de educação infantil. Cadernos de Pesquisa, v. 36, n. 129, p. 547-571, set./dez. 2006. Disponível em: http://www.scielo.br/pdf/cp/v36n129/a 0336129.pdf. Acesso em 24/03/2011.

OSTETTO, Luciana Esmeralda. Encontros e encantamentos na educação infantil: Partilhando experiências de estágios. Campinas: Papirus, 4.ed. 2000.

OSTETTO, Luciana Esmeralda (org.). Educação infantil: saberes e fazeres da formação de professores. Campinas: Papirus, 4.ed. 2008.

QUADROS, Marivete Bassetto de. Monografias, dissertações \& cia: caminhos metodológicos e normativos. 2.ed. ver. Curitiba: Tecnodata Educacional, 2009.

QUADROS, Marivete Bassetto de. Projeto de pesquisa: texto em re-construção. UENP - Centro de Ciências Humanas e da Educação - Pedagogia. Jacarezinho, 2010. [mimeo].

SEFFNER, Fernando. Cruzamento entre gênero e sexualidade na ótica da construção da(s) identidade(s) e da(s) diferença(s). In: SOARES, Guiomar Freitas; SILVA, Meri Rosane Santos da.

VASCONCELOS, Geni Amélia Nader (org). Como me fiz professora. Rio de Janeiro: DP\&A, 2000.

ZAGURY, Tânia. O professor refém: para os pais e professores entenderem por que fracassa a educação no Brasil. Rio de Janeiro: Record, 2006.

\section{Como referenciar este artigo}

MONTEIRO, Solange Aparecida de Souza.; RIBEIRO, Paulo Rennes Marçal. Atuação do pedagogo e as questões de gênero e identidade na educação infantil. Temas em Educ. e Saúde, Araraquara, v. 15, n. 1, p. 93-112, jan./jun., 2019. e-ISSN 2526-3471. ISSN 1517-7947. DOI: $10.26673 /$ tes.v15i1.12771

Submetido em: 02/11/2018

Aprovado em: 30/03/2019 